\title{
Immunogenicity Specimen Assessments Reference Identifier
}

National Cancer Institute

\section{Source}

National Cancer Institute. Immunogenicity Specimen Assessments Reference Identifier. NCI Thesaurus. Code C117553.

A sequence of characters used to identify, name, or characterize the immunogenicity specimen assessments reference. 